\title{
Optimizing irrigation rate in a sandy loam soil using a numerical approach
}

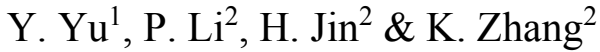 \\ ${ }^{1}$ College of Civil Engineering and Architecture, \\ Zhejiang University, China \\ ${ }^{2}$ Ningbo Institute of Technology, Zhejiang University, China
}

\begin{abstract}
Inappropriate irrigation often leads to agricultural water waste via surface runoff and drainage to the deep soil. In this paper an investigation was carried out to determine optimal irrigation rate and time for crops grown in a sandy loam soil using the Hydrus-1D model. The threshold of soil water content in the root zone for irrigation was assumed to be the soil water content at which a half of readily available water was depleted in the root zone. The simulations for soil water content in the profile immediately after irrigation and $24 \mathrm{~h}$ after irrigation were performed with various irrigation rate and time, ranging from $1 \mathrm{~cm} / \mathrm{h}$ and $3 \mathrm{~cm} / \mathrm{h}$ for $1 \mathrm{~h}$ to $3 \mathrm{~h}$. The simulated results showed that no surface runoff was occurred for the sandy loam soil, even under the rate of $3 \mathrm{~cm} / \mathrm{h}$ irrigated for $3 \mathrm{~h}$. The soil wetting depth $24 \mathrm{~h}$ after irrigation increased with the irrigation amount in an approximately linear manner. For the irrigation rate of $1 \mathrm{~cm} / \mathrm{h}$, the wetting depth was about $14.6 \mathrm{~cm}$ immediately after $1 \mathrm{~h}$ irrigation, and increased to $27.2 \mathrm{~cm}$ $24 \mathrm{~h}$ afterwards, compared with $27.8 \mathrm{~cm}$ and $58.6 \mathrm{~cm}$ for the irrigation rate of $3 \mathrm{~cm} / \mathrm{h}$. For a given irrigation amount, the distribution of soil water content was identical $24 \mathrm{~h}$ after irrigation, regardless of the irrigation rate. Furthermore, considerable expansion of the wetted soil area for different irrigation rate was also simulated due to soil water re-distribution. The results from this study implied that: 1) the expansion of the wetted area induced by soil water redistribution needed to be taken into consideration for irrigation planning; 2) the entire root zone for a wide range of crops could be wetted with a single irrigation event; and 3) there were choices in terms of irrigation rate and time to bring up soil water content in the root zone.

Keywords: Hydrus-1D, precision agriculture, agricultural water management, optimal irrigation.
\end{abstract}




\section{Introduction}

Saving agricultural water is of great importance for sustainable development of agriculture and for the protection of the environment. Agriculture has already consumed $70 \%$ of fresh water worldwide [1] and a large amount of irrigated water was wasted [2]. Overuse of water in agriculture could reduce crop yield, comprise produce quality, increase the production cost, and also cause great damage to the environment. Urgent actions are therefore required to save water use in agriculture via optimising irrigation practices.

Great efforts have been invested to devise irrigation scheduling. There have been reports of using crop monitoring techniques such as thermal imaging, leaf thickness, leaf wetness for this purpose. Perhaps more commonly, soil sensors detecting soil water content or water potential have been used to control irrigation [3-7]. The sensor-based irrigation systems, which are increasingly becoming available, made irrigation decisions based on real-time sensor readings in the root zone. Although these approaches could determine when to irrigate (but usually too late for crop monitoring techniques), they could not decide the amount required to irrigate.

Precise determination of irrigation amount is a rather difficult task, since it relates a number of factors such as soil texture, crop growth stages and rooting depth, and weather [8]. Although temporal-spatial soil water content could be measured experimentally during and after irrigation for various soil types subject to different irrigation rate and time, it is labour-intensive and difficult to conduct systematically. The numerical approaches, empirical or mechanistic, have provided a good solution to this problem [9]. Amongst all the empirical methods, the Green-Ampt equation and its variations might be used most widely for determining water infiltration in the soil [10]. It assumes a sharp wetting front separating the upper saturated zone and the lower unsaturated zone. The biggest advantage of this approach is its ease-to-use of the equation. However, the assumption of a sharp wetting front is over simplified, especially for fine soils. Also, it cannot predict the re-distribution of soil water, which could be a great amount in coarse soils. On the other hand, the theory of the Richards' equationbased numerical approach is well established for water infiltration and water movement in the soil and the develop software is readily available. The models of its kind are now accurate enough to make good predictions, and are playing an important role in precision agriculture [9]. The HYDRUS-1D is a universal model for predicting water movement and solute transport in porous media, and has widely been used for various purposes [11]. Its effectiveness and accuracy in predicting soil water movement have well been documented in a large body of literature [12]. The HYDRUS-1D model could simulate the response of soil water content in the profile to the various irrigation rate and time, and could thus be employed in irrigation planning.

The objectives of this study were to: 1) systematically simulate soil water content distribution immediately after irrigation and $24 \mathrm{~h}$ after irrigation for a sandy loam soil subject to various irrigation rate and time; 2) compare soil water content distribution for a given irrigation amount administrated with different 
irrigation rate and time; and 3) observe the changes in soil water content and in the wetting front caused by soil water re-distribution.

\section{Materials and methods}

\subsection{Soil water flow equation}

The HYDRUS-1D model was developed by Šimůnek et al. [11] for simulating water movement and solute transport in variably-saturated porous media. It has been widely used in modelling soil water flow and in predicting soil water content by solving the Richards' equation via a finite element scheme. It processes the advantage of dealing with complex media and flexible boundary conditions [11]. For a homogeneous and isotropic soil in a 1-D situation, the Richards' equation without a sink term can be expressed as follows:

$$
\frac{\partial \theta}{\partial t}=\frac{\partial}{\partial z}\left[K(\theta)\left(\frac{\partial h}{\partial z}+1\right)\right]
$$

where $\theta$ is the volumetric soil water content $\left(\mathrm{cm}^{3} / \mathrm{cm}^{3}\right), t$ is the time (h), $z$ is the vertical coordinate (positive upwards) with its origin at the soil surface $(\mathrm{cm}), h$ is the soil water pressure head $(\mathrm{cm}), K(\theta)$ is the soil hydraulic conductivity $(\mathrm{cm} / \mathrm{h})$.

\subsection{Computational domain, boundary and initial conditions}

A soil column of $100 \mathrm{~cm}$ subject to various irrigation rate and irrigation time was simulated for water infiltration, surface runoff and temporal-spatial soil water content in the profile. The soil was a sandy loam soil characterised in Šimůnek et $a l$. [11]. The simulated domain was equally divided into 500 layers with the layer thickness of $0.2 \mathrm{~cm}$ each.

The upper boundary condition was set as the atmospheric, i.e. the irrigation volume was treated as precipitation as the input of the model. No soil evaporation was considered, since the simulations were carried out only for a short period of time. The lower boundary condition was specified as free drainage.

The initial soil water content in the computed domain was identical as that by Li et al. [13], i.e. the average soil water content at field capacity $\theta_{F C}$ and at the permanent wilting point $\theta_{P W P}$. This is the soil water content at which $50 \%$ of total available water is depleted by plants, and below which root water uptake is reduced and crop growth is compromised for most crops according to Allen et al. [14], and is thus set as a threshold for irrigation.

\subsection{Model parameterisation and simulated scenarios}

The van Genuchten hydraulic parameter values for the sandy loam soil used in this study were taken from Šimůnek et al. [11] and are shown in Table 1. Also shown in Table 1 are the values of soil water content at field capacity and the 
permanent wiling point. The definition of field capacity is the water content retained in soil at $-330 \mathrm{~cm}$ of hydraulic water head [15].

Table 1: The van Genuchten soil hydraulic parameter values [11] and characteristic water content used in the simulations*.

\begin{tabular}{|c|c|c|c|c|c|c|}
\hline $\begin{array}{c}\theta_{s} \\
\left(\mathrm{~cm}^{3} / \mathrm{cm}^{3}\right)\end{array}$ & $\begin{array}{c}\theta_{r} \\
\left(\mathrm{~cm}^{3} / \mathrm{cm}^{3}\right)\end{array}$ & $\begin{array}{c}\alpha \\
(1 / \mathrm{cm})\end{array}$ & $\begin{array}{c}n \\
(-)\end{array}$ & $\begin{array}{c}K_{s} \\
(\mathrm{~cm} / \mathrm{h})\end{array}$ & $\begin{array}{c}\theta_{\mathrm{FC}} \\
\left(\mathrm{cm}^{3} / \mathrm{cm}^{3}\right)\end{array}$ & $\begin{array}{c}\theta_{P W P} \\
\left(\mathrm{~cm}^{3} / \mathrm{cm}^{3}\right)\end{array}$ \\
\hline 0.410 & 0.065 & 0.075 & 1.89 & 4.42 & 0.085 & 0.066 \\
\hline
\end{tabular}

${ }^{*} \theta_{r}$ and $\theta_{s}\left(\mathrm{~cm}^{3} / \mathrm{cm}^{3}\right)$ are the residual water content and the saturated water content, $\alpha$ and $n$ are the shape parameters, $K_{s}(\mathrm{~cm} / \mathrm{h})$ is the saturated hydraulic conductivity.

During the simulations, three irrigation rates of $1 \mathrm{~cm} / \mathrm{h}, 2 \mathrm{~cm} / \mathrm{h}$ and $3 \mathrm{~cm} / \mathrm{h}$ were assumed, and the irrigation time was $1 \mathrm{~h}, 2 \mathrm{~h}$ and $3 \mathrm{~h}$, respectively. The total irrigation amount ranged from $1 \mathrm{~cm}$ to $9 \mathrm{~cm}$, which was a reasonable applied amount of water in a single event. The simulation period was $24 \mathrm{~h}$ from the start of irrigation.

\section{Results and discussion}

A total of nine scenarios, namely RxTy with $\mathrm{x}$ being irrigation rate in $\mathrm{cm} / \mathrm{h}$ and $\mathrm{y}$ being irrigation time in $\mathrm{h}$, were simulated in this study. The output of the HYDRUS-1D model included surface runoff during irrigation, and temporalspatial water content distribution along the soil profile for the simulation period. No runoff was simulated in all the scenarios studied.

\subsection{Soil water content distribution immediately after irrigation and $24 \mathrm{~h}$ after irrigation}

Figure 1 shows the distribution of water content along the soil profile immediately after irrigation and $24 \mathrm{~h}$ after irrigation under different irrigation rate of $1 \mathrm{~cm} / \mathrm{h}, 2 \mathrm{~cm} / \mathrm{h}$, and $3 \mathrm{~cm} / \mathrm{h}$ irrigated for $1 \mathrm{~h}, 2 \mathrm{~h}$ and $3 \mathrm{~h}$ (i.e. scenarios R1T1, R2T2 and R3T3), respectively, as examples. It is clear that in all the simulated scenarios with the total irrigation amount ranging from $1 \mathrm{~cm}$ to $9 \mathrm{~cm}$ the soil in the wet region near its saturation immediately after irrigation. Soil water content decreased rapidly from near saturation to the initial value in a very small region at the bottom in the wetted soil. For example, in the scenario R3T3, soil water content decreased from $0.33 \mathrm{~cm}^{3} / \mathrm{cm}^{3}$ to the initial value of $0.075 \mathrm{~cm}^{3} / \mathrm{cm}^{3}$ in a depth of $2 \mathrm{~cm}$ in the bottom of the wet region. Such a phenomenon could be explained by the fact that the sandy loam soil has big pores in the medium, and thus has a great capacity of drainage. Water movement in the soil is mainly driven by gravity and not so much by soil water potential resulting from soil pores. 


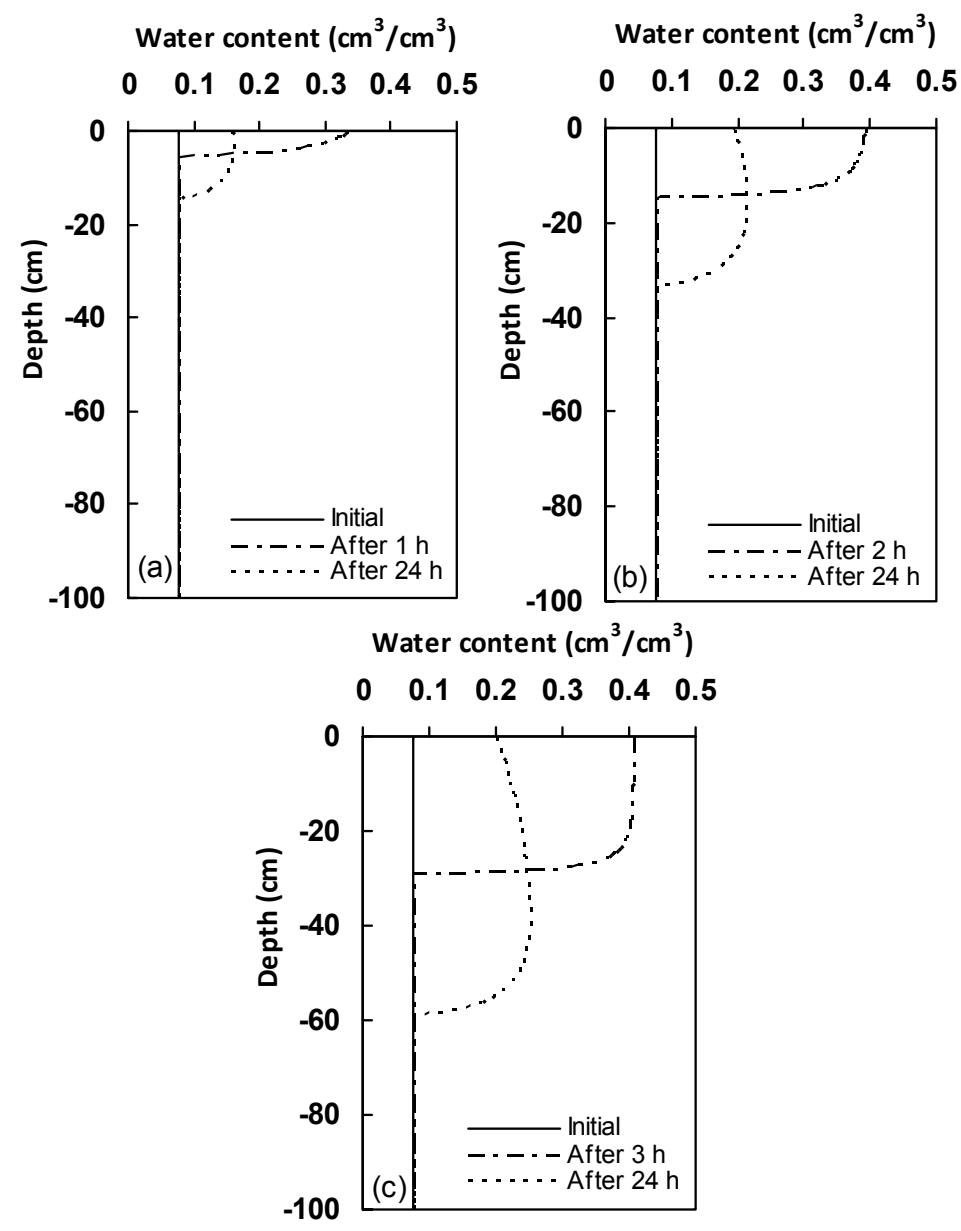

Figure 1: Soil water content distribution along the profile immediately after irrigation and $24 \mathrm{~h}$ after irrigation with irrigation rate of $1 \mathrm{~cm} / \mathrm{h} \mathrm{(a)}$, $2 \mathrm{~cm} / \mathrm{h}(\mathrm{b})$ and $3 \mathrm{~cm} / \mathrm{h}(\mathrm{c})$.

The distribution of soil water content is rather different after re-distribution. It can be seen, from Figure 1, a large proportion of irrigated water re-distributed itself. In the scenario R3T3, the irrigated water was stored in the top $27.8 \mathrm{~cm}$ soil immediately after irrigation. However, after $24 \mathrm{~h}$ the wetting front moved to the depth of $58.6 \mathrm{~cm}$, and $51.3 \%$ of irrigated water was contained below the $29 \mathrm{~cm}$ depth. Contrary to that immediately after irrigation, soil water content could increase with increasing depth, resulting in more water stored in the deeper soil. The biggest soil water content of $0.25 \mathrm{~cm}^{3} / \mathrm{cm}^{3}$ occurred at the depth of $40.0 \mathrm{~cm}$, compared with $0.20 \mathrm{~cm}^{3} / \mathrm{cm}^{3}$ at the soil surface. This could also be attributed to the big drainage capacity associated with a small water holding capacity in the sandy loam soil. 


\subsection{Variation of soil water content with time}

Figure 2 illustrates the variation of soil water content with time at the depth of $10 \mathrm{~cm}$ for the irrigation amount of $2 \mathrm{~cm}$ (scenarios R1T2 and R2T1) and of $6 \mathrm{~cm}$ (scenarios R2T3 and R3T2). Despite the difference in time when soil water content started increasing, the changes patterns in soil water content were similar between the scenarios R1T2 and R2T1, and the scenarios R2T3 and R3T2. It also reveals that the drastic change in soil water content happened in the first $5 \mathrm{~h}$. Soil water content decreased at a much slower pace afterwards, and stabilised at $10 \mathrm{~h}$ after the start of irrigation.
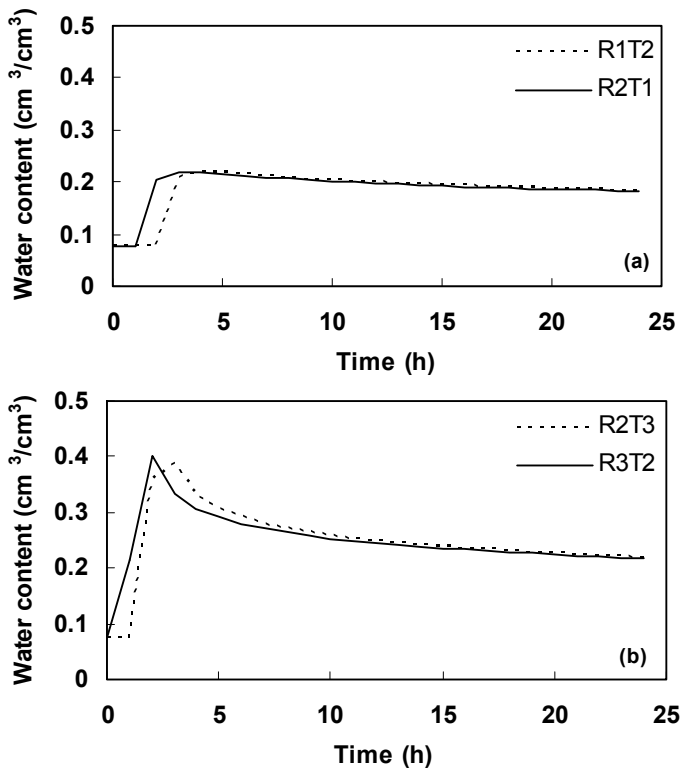

Figure 2: Variation of soil water content with time at the depth of $10 \mathrm{~cm}$ for the scenarios R1T2 and R2T1 (a) and the scenarios R2T3 and R3T2 (b).

\subsection{Comparison of soil water content distribution for a given irrigation amount}

Comparison of soil water content distribution immediately after irrigation and $24 \mathrm{~h}$ after irrigation for a given irrigation amount was carried out (Figure 3). As a comparison Figure 3 shows soil water content distribution for the irrigation amount of $2 \mathrm{~cm}$ and $6 \mathrm{~cm}$. There exist some differences in soil water content distribution immediately after irrigation (between scenarios R1T2 and R2T1, and R2T3 and R3T2) due to the different irrigation rate and time. However, soil water content distribution was identical $24 \mathrm{~h}$ after irrigation for a given irrigation amount. This indicates that the redistribution of soil water content was dominated by the total irrigation amount, not the irrigation rate and time. 

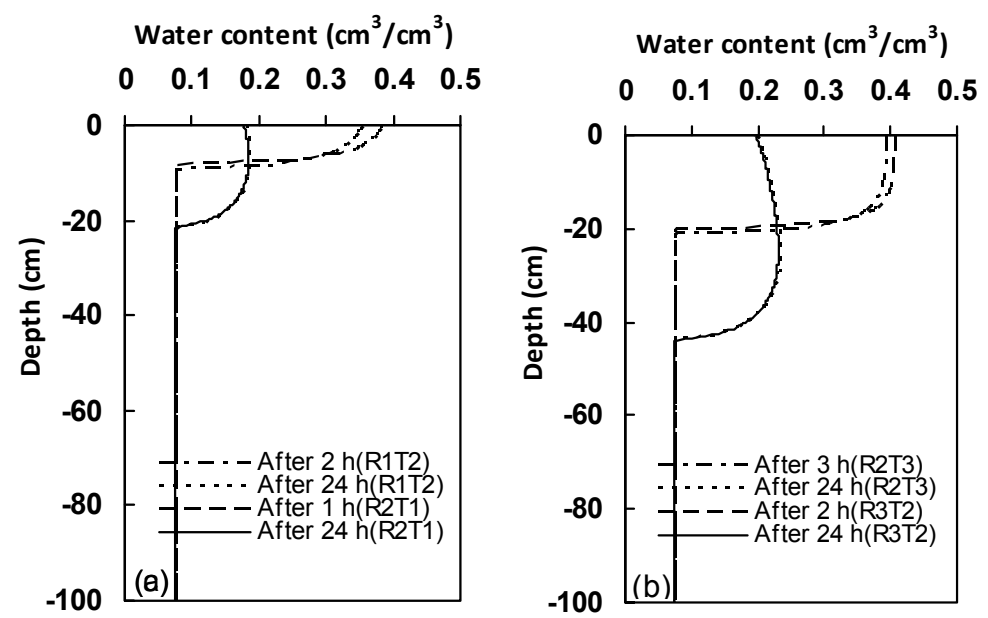

Figure 3: Comparison of soil water content distribution immediately after irrigation and $24 \mathrm{~h}$ after irrigation between the scenarios R1T2 and R2T1 (a), and scenarios R2T3 and R3T2 (b).

Figure 4 shows the relationship between the soil wetting depth and irrigation amount $24 \mathrm{~h}$ after irrigation for all the scenarios. Apparently, the soil wetting depth was highly correlated with the irrigation amount. For every $\mathrm{cm}$ of irrigated water, the increase in the wetting depth was $5.5 \mathrm{~cm}$.

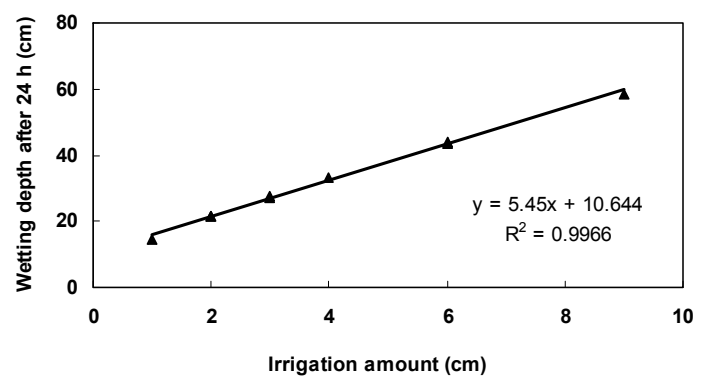

Figure 4: Relationship between the soil wetting depth and irrigation amount $24 \mathrm{~h}$ after irrigation for all the scenarios.

\subsection{Variation of soil wetting depth with time}

Figure 5 shows the advance of the soil wetting front with time for the irrigation amount of $2 \mathrm{~cm}$ and $6 \mathrm{~cm}$. It is obvious that in both cases that the wetting depth increased faster during the irrigation period. Also, it can be seen that at the beginning of irrigation soil wetting depth increased faster for the bigger irrigation rate. In the scenario R2T1 the wetting depth was $8.0 \mathrm{~cm}$ immediately after $1 \mathrm{~h}$ irrigation, while the corresponding value was $5.2 \mathrm{~cm}$ in the scenario 
R1T2. The difference in the soil wetting depth between two different scenarios disappeared $5 \mathrm{~h}$ after irrigation started. Although there is a trend that the soil wetting depth increased with time even at the late simulation period, the change in the wetting depth appeared ignorable $24 \mathrm{~h}$ after irrigation.
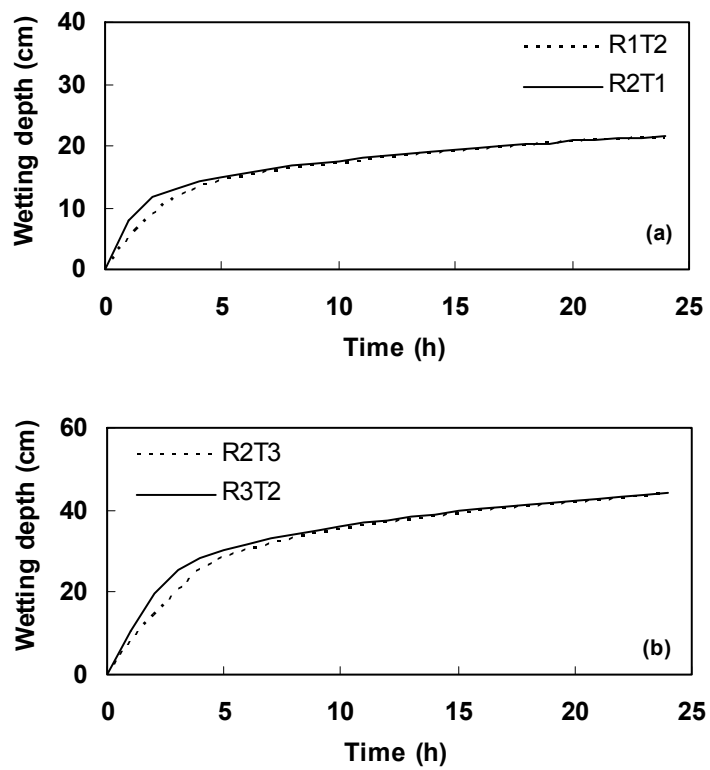

Figure 5: Variation of soil wetting depth with time in the scenarios R1T2 and R2T1 (a), and the scenarios R2T3 and R3T2 (b).

\section{Conclusions}

In this study a numerical investigation into the changes in temporal-spatial of water content and the wetting front of a sandy loam soil subject to different irrigation rate and time was carried out. Based on the results presented the above, it could be concluded that: 1) irrigated water was stored in the soil near the surface with water content close to saturation immediately after irrigation; 2) a great amount of irrigated water re-distributed, resulting in more water stared in the deeper soil; 3) the change in the soil wetting depth was great and should therefore be taken into consideration in devising irrigation plans.

\section{References}

[1] Food and Agriculture Organization of the United Stations (FAO), Crops and Drops - Making the Best Use of Water for Agriculture. FAO: Rome, Italy, 2002.

[2] http://wwf.panda.org/about_our_earth/about_freshwater/freshwater_proble ms/thirsty_crops/ 
[3] Stanley, C.D. \& Maynard, D.N., Vegetables. Irrigation of Agricultural Crops, eds. B.A. Stewart \& D.R. Nielsen, Madison, WI: ASA CSSA SSSA, pp. 921-950, 1990.

[4] Munoz-Carpena, R., Dukes, M.D., Li, Y.C. \& Klassen, W., Field comparison of tensiometer and granular matrix sensor automatic drip irrigation on tomato. Horttechnology, 15, pp. 584-590, 2005.

[5] Wang, F.X., Kang, Y., Liu, S.P. \& Hou, X.Y., Effects of soil matric potential on potato growth under drip irrigation in the North China Plain. Agricultural Water Management, 88, pp. 34-42, 2007.

[6] Vellidis, G., Tucker, M., Perry, C., Kvien, C. \& Bednarz, C., A real-time wireless smart sensor array for scheduling irrigation. Computers and Electronics in Agriculture, 61, pp. 44-50, 2008.

[7] Cardenas-Lailhacar, B. \& Dukes, M.D., Precision of soil moisture sensor irrigation controllers under field conditions. Agricultural Water Management, 97, pp. 666-672, 2010.

[8] Greenwood, D.J., Zhang, K., Hilton, H.W. \& Thompson, A.J., Opportunities for improving irrigation efficiency with quantitative models, soil water sensors and wireless technology. Journal of Agricultural Science, 148, pp. 1-16, 2010.

[9] Bastiaanssen, W.G.M., Allen, R.G., Droogers, P., D’Urso, G. \& Steduto, P., Twenty-five years modeling irrigated and drained soils: State of the art. Agricultural Water Management, 34, pp. 137-148, 2007.

[10] Ma, Y., Feng, S., Su, D., Gao, G. \& Huo, Z., Modeling water infiltration in a large layered soil column with a modified Green-Ampt model and HYDRUS-1D. Computers and Electronics in Agriculture, 71S, pp. S40S47, 2010.

[11] Šimůnek, J., Šejna, M., Saito, H., Sakai, M. \& van Genuchten, M. Th., The HYDRUS-1D Software Package for Simulating One-Dimensional Movement of Water, Heat, and Multiple Solutes in Variably-Saturated Media, Version 4.16. Department of Environmental Sciences, University of California Riverside, Riverside, California, p. 305, 2013.

[12] Šimůnek, J., van Genuchten, M. Th. \& Kodešová, R., (eds). Proceedings of the 4th International Conference "HYDRUS Software Applications to Subsurface Flow and Contaminant Transport Problems", Department of Soil Science and Geology, Czech University of Life Sciences, Prague, Czech Republic, p. 404, 2013.

[13] Li, P., Wu, F. \& Zhang, K., Numerical investigation into optimal agricultural water management for typical soils using HYDRUS-1D model. Journal of Agriculture, Food and Environment, 12, pp. 155-160, 2014.

[14] Allen, R.G., Oereira, L.S., Raes, D. \& Smith, M., Crop Evapotranspiration - FAO Irrigation and Drainage Paper No. 56. FAO, p. 300. Rome 300: 6541, 1998.

[15] Saxton, K.E. \& Rawls, W.J., Soil water characteristic estimates by texture and organic matter for hydrologic solutions. Soil Science Society of America Journal, 70, pp. 1569-1578, 2006. 